\title{
ANALISIS SALURAN PEMASARAN SALE PISANG (Studi Kasus pada Perajin Sale Pisang Basah di Desa Sindangbarang Kecamatan Karangpucung Kabupaten Cilacap)
}

\author{
ANDI NUGROHO ${ }^{1 *}$, DINI ROCHDIANI ${ }^{2}$, MUHAMAD NURDIN YUSUF ${ }^{1}$ \\ ${ }^{1}$ Fakultas Pertanian Universitas Galuh \\ ${ }^{2}$ Fakultas Pertanian Universitas Padjadjaran \\ *E-Mail: andinugroho012@gmail.com
}

\begin{abstract}
ABSTRAK
Rantai pemasaran yang panjang dengan banyaknya lembaga pemasaran yang terlibat semakin memperkecil keuntungan yang diperoleh perusahaan. Penelitian ini bertujuan untuk mengetahui saluran, biaya, margin, dan keuntungan pemasaran serta share. Metode yang digunakan adalah kualitatif dengan jenis studi kasus pada perajin pisang basah di Desa Sindangbarang Kecamatan Karangpucung Kabupaten Cilacap. Data yang digunakan adalah data primer dan data sekunder. Sementara itu lembaga pemasaran yang terlibat dalam proses pemasaran sale pisang basah ditentukan menggunakan snowball sampling. Hasil penelitian menunjukkan bahwa: Terdapat tiga saluran pemasaran yaitu saluran pemasaran 0 (nol), 1 (satu), dan dua (dua) tingkat. Biaya terbesar diperoleh pedagang pengecer $\mathrm{Rp} 1.131$,- per kg. Marjin terbesar diperoleh pedagang pengecer $\mathrm{Rp} 4.500$,- per $\mathrm{kg}$. Keuntungan terbesar yang diperoleh pedagang pengecer $\mathrm{Rp} 4.118,-$ per $\mathrm{kg}$. Bagian harga yang diterima perajin (share) pada saluran pemasaran 1 adalah 100 persen, saluran pemasan 2 paling adalah 83 persen, dan saluran pemasaran 3 adalah 80 persen.
\end{abstract}

Kata kunci : Perajin, saluran pemasaran, sale pisang basah.

\begin{abstract}
A long marketing chain with many marketing institutions involved reduces the profits of the company. This study aims to determine the channels, costs, margins, and marketing and share benefits. The method used is qualitative with a type of case study on wet banana crafters in Sindangbarang Village, Karangpucung District, Cilacap Regency. The data used are primary data and secondary data. Meanwhile the marketing institutions involved in the marketing process of the sale of wet bananas are determined using snowball sampling. The results showed that: There are three marketing channels namely 0 (zero), 1 (one), and two (two) level marketing channels. The biggest cost is obtained by retailers $\mathrm{Rp} 1,131$ per $\mathrm{kg}$. The biggest margin was obtained by retailers at $\mathrm{Rp} \mathrm{4,500} \mathrm{per} \mathrm{kg}$. The biggest profit gained by retailers is $\mathrm{Rp} 4,118$ per $\mathrm{kg}$. The share of the price received by the craftsman (share) on marketing channel 1 is 100 percent, channel 2 is at most 83 percent, and marketing channel 3 is 80 percent.
\end{abstract}

Keywords: Crafters, marketing, banana sale.

\section{PENDAHULUAN}

\section{Latar Belakang}

Agroindustri sale pisang di Desa Sindangbarang sudah lama diusahakan dengan kapasitas produksi 780 ton per tahun (Desa Sindangbarang, 2017). Rantai pemasaran yang panjang dengan banyaknya lembaga pemasaran yang terlibat semakin memperkecil keuntungan yang diperoleh perusahaan. Menurut Mainura (2014), apabila saluran pemasaran panjang dan tidak lancar akan mengakibatkan pendapatan yang diperoleh perajin atau produsen semakin sedikit 
karena biaya pemasaran yang dikeluarkan lebih tinggi daripada harga jual sale pisang basah itu sendiri. Sebaliknya jika pemasarannya efisien, maka akan memberikan bagian pendapatan yang adil antara perajin sebagai produsen, konsumen sebagai pemakai barang serta lembagalembaga yang ikut dalam proses pemasaran tersebut.

Penelitian ini bertujuan untuk mengetahui saluran, biaya, margin, dan keuntungan pemasaran serta share.

\section{METODE PENELITIAN}

Metode yang digunakan dalam penelitian ini adalah kualitatif dengan jenis studi kasus pada perajin sale pisang basah di Desa Sindangbarang Kecamatan Karangpucung Kabupaten Cilacap.

Data yang digunakan dalam penelitian yaitu data primer dan sekunder. Data primer didapat lewat wawancara langsung terhadap perajin secara terstruktur. Sementara data sekunder diperoleh melalui studi kepustakaan dan studi dokumentasi dari dinas dan instansi terkait.

Lokasi penelitian ditentukan secara sengaja (purposive) pada pengusaha agroindustri Sale Pisang Basah di Desa Sindangbarang Kecamatan Karangpucung Kabupaten Cilacap dengan pertimbangan jumlah pengusaha dan kapasitas produksi yang paling banyak dibandingkan dengan yang lain. Arikunto (2006) menyatakan bahwa purposive sampling adalah menentukan sampel dengan pertimbangan tertentu yang dipandang dapat memberikan data secara maksimal.

Sampling responden ditentukan menggunakan total sampling, artinya seluruh elemen populasi seluruhnya dijadikan sampel yaitu sebanyak 4 orang perajin sale pisang basah. Sugiyono (2014) menyatakan total sampling yaitu teknik pengambilan sampel dimana jumlah sampel sama dengan populasi.

Sementara itu lembaga pemasaran yang terlibat dalam proses pemasaran sale pisang basah ditentukan menggunakan snowball sampling. Menurut Sugiyono (2001) snowball sampling adalah teknik penentuan sampel yang awalnya berjumlah kecil, lalu sampel ini diminta memilih teman-temannya untuk dijadikan sampel

Alat analisis yang digunakan terdiri atas:

1. Saluran pemasaran dianalisis secara deskripitif.

2. Marjin pemasaran menggunakan rumus dari Angipora (2002):

$$
\begin{aligned}
& M m=P e-P f \\
& M m=\text { Marjin pemasaran } \\
& P e=\text { Harga produk di tingkat pemasaran } \mathrm{Rp} / \mathrm{kg}
\end{aligned}
$$


$P f=$ Harga produk di tingkat produsen $R p / k g$

Karena di marjin pemasaran terdapat dua komponen yaitu komponen biaya dan komponen keuntungan maka digunakan rumus (Angipora, 2002) :

$M m=\pi+T C^{2}$

$\pi=M n+T C$

$M m=$ Marjin pemasaran di tingkat produsen

$\pi=$ keuntungan di tingkat lembaga pemasaran

$T C$

$=$ Total Cost $($ Total biaya pemasaran di tingkat lembaga pemasaran

3. Bagian harga yang diterima produsen (producer's share) menggunakan rumus (Angipora, 2002):

$$
\begin{aligned}
& P S=\frac{H f}{H e} \times 100 \% \\
& P S=\text { Bagian harga yang diterima produsen (Producer'sshare) } \\
& H f=\text { Harga di tingkat produsen } R p / \mathrm{kg} \\
& H e=\text { Harga di tingkat lembaga pemasaran } R p / \mathrm{kg}
\end{aligned}
$$

\section{HASIL DAN PEMBAHASAN}

\section{Identitas Responden}

Jumlah responden adalah sebanyak 15 orang terdiri dari 3 orang perajin sale pisang, 1 orang pedangang pengumpul, 11 pedagang pengecer. Semua perajin berada di Desa Sindangbarang, seorang pedagang pengumpul berada di Kecamatan Cimanggu, sedangkan 11 orang pengecer berada di Kecamatan Majenang,
Kecamatan Wanareja, Kecamatan Lakbok, Purokerto, dan di Kecamatan Antapani Kota Bandung.

\section{Umur}

Berdasarkan hasil wawancara usia responden antara 26 tahun sampai 70 tahun, dengan rata-rata berumur 46 tahun. Hasil ini menunjukan bahwa usia responden umumnya pada usia produktif yaitu usia 15 sampai 64 tahun (Suratiyah, 2006).

\section{Tingkat Pendidikan}

Tingkat pendidikan responden didominasi oleh lulusan Sekolah Menengah Atas (SMA), yang akan berengaruh terhadap pengembangan usaha sale pisang dan pemasarannya. Hal ini berdampak pada pola pikir yang cenderung menerima perubahan menjadi lebih baik serta cenderung memiliki pandangan dan pengetahuan yang fleksibel.

\section{Tanggungan Keluarga}

Rata-rata responden mempunyai tanggungan keluarga 2 orang. Hal ini disebabkan anak yang masih tinggal satu rumah belum berkeluarga dan masih menjadi tanggungjawab keluarga. Semua tanggungan keluarga ini terdiri dari istri dan anak yang masih tinggal satu rumah. 


\section{Pengalaman Responden dalam Agroindustri Sale Pisang Basah}

1) Saluran pemasaran 1

2) Saluran pemasaran 2

Produsen

3) Saluran pemasaran 3

Produsen

Hasil
Gambar 1 menunjukan rata-rata pengalaman berusaha perajin sekitar 13 tahun, pengalaman berusaha pedagang pengumpul 8 tahun, sedangkan pengalaman pedagang pengecer 13 tahun. Berdasarkan pengalaman yang telah dimiliki oleh perajin maupum lembaga pemasaran diharapkan lebih baik lagi, sehingga dapat meningkatkan skala usaha dan mampu meningkatkan pendapatan. Kemudian bagi lembaga pemasaran semakin lama pengalaman berusaha semakin cepat dalam memasarkan produknya.

\section{Saluran Pemasaran Sale Pisang Basah}

Hasil penelitian diketahui bahwa : Terdapat tiga saluran pemasaran: penelitian menunjukan pula bahwa terdapat tiga saluran pemasaran sale pisang yaitu saluran nol tingkat, satu tingkat, dan dua tingkat. 2 Perajin (66\%) melaukan saluran 1 dan 2, dan 1 perajin (34\%) yang melakukan saluran 1, 2, dan 3. 
Biaya, Marjin, dan Keuntungan Pemasaran Sale Pisang Basah

Tabel 1. Rincian Biaya dan Keuntungan Pemasaran Sale Pisang Basah di Desa Sindangbarang Kecamatan Karangpucung Kabupaten Cilacap

\begin{tabular}{|c|c|c|c|c|}
\hline \multirow{2}{*}{ No } & \multirow{2}{*}{ Uraian Pada Perajin 1} & \multicolumn{3}{|c|}{ Saluran Pemasaran } \\
\hline & & Saluran 1 Rp/ Kg & Saluran 2 Rp/ kg & Saluran 3 Rp/ kg \\
\hline 1 & Produsen & 20.000 & 20.000 & \\
\hline \multirow[t]{4}{*}{2} & Pedagang Pengecer 1 & & & \\
\hline & - $\quad$ Harga Beli & & 20.000 & \\
\hline & - $\quad$ Harga Jual & & 25.000 & \\
\hline & - $\quad$ Biaya Pengangkutan & & 1.000 & \\
\hline \multirow[t]{5}{*}{3} & Pedagang Pengecer 2 & & & \\
\hline & - $\quad$ Harga Beli & & 20.000 & \\
\hline & - $\quad$ Harga Jual & & 25.000 & \\
\hline & - $\quad$ Biaya Pengangkutan & & 1.000 & \\
\hline & - $\quad$ Biaya Pengemasan & & 200 & \\
\hline \multirow[t]{5}{*}{4} & Pedagang Pengecer 3 & & & \\
\hline & - $\quad$ Harga Beli & & 20.000 & \\
\hline & - $\quad$ Harga Jual & & 26.000 & \\
\hline & - $\quad$ Biaya Pengangkutan & & 1.000 & \\
\hline & - $\quad$ Biaya Pengemasan & & 225 & \\
\hline \multirow[t]{5}{*}{5} & Pedagang Pengecer 4 & & & \\
\hline & - $\quad$ Harga Beli & & 20.000 & \\
\hline & - $\quad$ Harga Jual & & 25.000 & \\
\hline & - $\quad$ Biaya Pengangkutan & & 1.000 & \\
\hline & - $\quad$ Biaya Pengemasan & & 100 & \\
\hline \multirow[t]{4}{*}{6} & Total & & & \\
\hline & Biaya (Harga rata-rata) & & 1.131 & \\
\hline & Margin (Harga rata-rata) & & 4.500 & \\
\hline & Keuntungan (Harga rata-rata) & 20.000 & 4.118 & \\
\hline 7 & Konsumen (Rata-rata) & 20.000 & 25.250 & \\
\hline \multirow{2}{*}{ No } & \multirow{2}{*}{ Uraian Pada Perajin 2} & \multicolumn{3}{|c|}{ Saluran Pemasaran } \\
\hline & & Saluran 1 Rp/ Kg & Saluran 2 Rp/ kg & Saluran 3 Rp/ kg \\
\hline 1 & Produsen & 20.000 & 20.000 & \\
\hline \multirow[t]{4}{*}{2} & Pedagang Pengecer 1 & & & \\
\hline & - $\quad$ Harga Beli & & 20.000 & \\
\hline & - $\quad$ Harga Jual & & 23.000 & \\
\hline & - $\quad$ Biaya Pengangkutan & & 500 & \\
\hline \multirow[t]{5}{*}{3} & Pedagang Pengecer 2 & & & \\
\hline & - $\quad$ Harga Beli & & 20.000 & \\
\hline & - $\quad$ Harga Jual & & 25.000 & \\
\hline & - $\quad$ Biaya Pengangkutan & & 1.000 & \\
\hline & - $\quad$ Biaya Pengemasan & & 266 & \\
\hline \multirow[t]{4}{*}{4} & Pedagang Pengecer 3 & & & \\
\hline & - $\quad$ Harga Beli & & 20.000 & \\
\hline & - $\quad$ Harga Jual & & 25.000 & \\
\hline & - $\quad$ Biaya Pengangkutan & & 1.000 & \\
\hline \multirow[t]{4}{*}{5} & Pedagang Pengecer 4 & & & \\
\hline & - $\quad$ Harga Beli & & 20.000 & \\
\hline & - $\quad$ Harga Jual & & 25.000 & \\
\hline & - $\quad$ Biaya Pengangkutan & & 1.000 & \\
\hline \multirow[t]{2}{*}{6} & Total & & & \\
\hline & Biaya (Harga rata-rata) & & 931 & \\
\hline
\end{tabular}




\begin{tabular}{|c|c|c|c|c|}
\hline & Margin (Harga rata-rata) & & 4.500 & \\
\hline & Keuntungan (Harga rata-rata) & 20.000 & 3.558 & \\
\hline 7 & Konsumen (Rata-rata) & 20.000 & 24.500 & \\
\hline \multirow{2}{*}{ No } & \multirow{2}{*}{ Uraian Pada Perajin 3} & \multicolumn{3}{|c|}{ Saluran Pemasaran } \\
\hline & & Saluran 1 Rp/ Kg & Saluran 2 Rp/ kg & Saluran 3 Rp/ kg \\
\hline 1 & Produsen & 20.000 & 20.000 & 20.000 \\
\hline \multirow[t]{4}{*}{2} & Pedagang Pengumpul & & & \\
\hline & - Harga Beli & & & 20.000 \\
\hline & - $\quad$ Harga Jual & & & 23.000 \\
\hline & - $\quad$ Biaya Pengangkutan & & & 1.000 \\
\hline \multirow[t]{4}{*}{3} & Pedagang Pengecer 1 & & & \\
\hline & - $\quad$ Harga Beli & & 20.000 & 23.000 \\
\hline & - $\quad$ Harga Jual & & 23.000 & 27.000 \\
\hline & - $\quad$ Biaya Pengangkutan & & 500 & 1.000 \\
\hline \multirow[t]{4}{*}{4} & Pedagang Pengecer 2 & & & \\
\hline & - $\quad$ Harga Beli & & 20.000 & \\
\hline & - $\quad$ Harga Jual & & 25.000 & \\
\hline & - $\quad$ Biaya Pengangkutan & & 1.000 & \\
\hline \multirow[t]{4}{*}{5} & Total & & & \\
\hline & Biaya (Harga rata-rata) & & 750 & 1.000 \\
\hline & Margin (Harga rata-rata) & & 4.000 & 3.500 \\
\hline & Keuntungan (Harga rata-rata) & & 3.500 & 2.500 \\
\hline 6 & Konsumen (Harga rata-rata) & 20.000 & 24.000 & 25.000 \\
\hline
\end{tabular}

Dapat disimpulkan, di saluran kedua biaya terbesar diperoleh pedagang pengecer (Rp 1.331 per $\mathrm{kg})$ dan keuntungan yang terbesar ada di pedagang pengecer pula ( $\mathrm{Rp} 4.118$ per $\mathrm{kg}$ ). Sedangkan pada saluran ketiga, biaya yang di tanggung pedagang pengumpul dan pengecer sama jumlahnya ( Rp 1.000 per $\mathrm{kg}$ ), dan keuntungan yang diperoleh $\mathrm{Rp}$ 2.500 per $\mathrm{kg}$.

\section{Producer's Share atau Persentase}

\section{Bagian Harga yang Diperoleh Perajin}

Pada saluran 1, besarnya nilai Producer's

Share adalah :

Producer's Share $=\frac{20000}{20000} \times 100 \%=100 \%$

Pada saluran 2, ada beberapa nilai Producer's Share sebagai berikut :
Producer's Share $=\frac{20000}{25250} \times 100 \%=79 \%$

Producer's Share $=\frac{20000}{24500} \times 100 \%=81 \%$

Producer's Share $=\frac{20000}{24000} \times 100 \%=83 \%$

Pada saluran 3, besarnya nilai Producer's

Share adalah :

Producer's Share $=\frac{20000}{25000} \times 100 \%=80 \%$

\section{KESIMPULAN DAN SARAN}

\section{Kesimpulan}

1. Hasil penelitian diketahui bahwa : Terdapat tiga saluran pemasaran : 1) Saluran pemasaran 1 ; Produsen $\rightarrow$ Konsumen. 2) Saluran pemasaran 2 ; Produsen $\rightarrow$ Pedagang Pengecer $\rightarrow$ Konsumen. 3) Saluran pemasaran 3 ; 
Produsen $\rightarrow$ Pedagang Pengumpul $\rightarrow$ Pedagang Pengecer $\rightarrow$ Konsumen.

2. Biaya terbesar diperoleh pedagang pengecer Rp 1.131 per kg. Marjin terbesar diperoleh pedagang pengecer Rp 4.500 per kg. Keuntungan terbesar yang diperoleh pedagang pengecer ( $\mathrm{Rp}$ 4.118 per $\mathrm{kg}$ )

3. Nominal harga yang diterima perajin (producer's share) pada saluran pemasaran 1 adalah $100 \%$, saluran pemasan 2 paling besar adalah $83 \%$, dan di saluran pemasaran 3 sebesar $80 \%$.

\section{Saran}

Berdasarkan kesimpulan, maka saran yang dapat disampaikan adalah perajin harus memperhatikan pemasaran dengan cara promosi yang baik melalui media cetak seperti brosur, dan menggunakan media sosial maupun media online lainnya karena cara ini dianggap efektif agar produk semakin dikenal luas dan secara online.

\section{DAFTAR PUSTAKA}

Angipora, 2002. Dasar-Dasar Pemasaran. Raja Grafindo Persada. Jakarta

Arikunto, S. 2006. Prosedur Penelitian suatu Pendekatan Praktik.. Rineka Cipta. Jakarta.

Desa Sindangbarang Kecamatan Karangpucung. 2017. Data Produksi Sale Pisang di Desa Sindangbarang Kecamatan Karangpucung. Cilacap.

Iskandar, 2009. Metodologi Penelitian dan Sosial. Jakarta. Gaung Persada Press.

Mainura, 2014. Analisis Nilai Tambah dan Sistem Pemasaran Pisang Sale di Kecatamatan Langkahan Kabupaten Aceh Utara. Jurusan Sosial Ekonomi Pertanian, Fakultas Pertanian. Universitas Syiah Kuala. Banda Aceh.

Sugiyono. 2001. Metode Penelitian Bisnis. Alfabeta. Bandung.

Sugiyono. 2014. Metode penelitian Kuantitatif Kualitatif . Universitas Muhammadiyah Malang. Malang.

Suratiyah, Ken. 2006. Ilmu Usaha Tani.Penebar Swadaya. Jakarta.

UMKM disperindagkop kabupaten Cilacap, 2017. Data Usaha Sale Pisang di Kabupaten Cilacap Tahun 2017. Cilacap. 